\title{
Dizziness profile and clinical features: a population based survey in São Paulo City, Brazil
}

\author{
Roseli Saraiva Moreira Bittar,' Raquel Mezzalira," Signe Schuster Grasel,' Jeanne Oiticica' \\ I - Universidade de São Paulo, São Paulo, Brazil II - Universidade de Campinas, Campinas, Brazil
}

OBJECTIVE: This is a cross-sectional epidemiological survey designed to estimate the prevalence of dizziness among the adult population of the city of São Paulo, Brazil, and to describe the clinical features and level of discomfort.

METHOD: This population based study was conducted in the city of São Paulo, Brazil, between April and October 2012. A total of 1,960 household interviews were completed. The following variables were assessed: gender, age, clinical characteristics of dizziness, and dizziness disability index. Chi-square test, Student's t-test, Tukey test and logistic regression were used for statistical analysis.

RESULTS: The dizziness prevalence in São Paulo was $42 \%$. Peaks of dizziness were observed in two age groups: $49 \%$ among the 46 to 55 year-old, and $44 \%$ among the elderly subjects ( $>65$ years-old). Vestibular vertigo was detected in $8.3 \%$ of patients, with a strong female preponderance $(p<0.001)$. Symptoms caused disability in $27 \%$ of the affected respondents and were more frequent among women $(p<0.001)$. These sought medical care more frequently $(p<0.001)$. The dizziness disability index was significantly higher $(p=0.0165)$ among subjects with a lower educational level. There was no correlation between dizziness discomfort and the type of job.

CONCLUSION: The prevalence of dizziness in São Paulo, Brazil, was established at $42 \%$. Among the symptomatic subjects, $67 \%$ reported interruption of daily activities, but only $46 \%$ of them sought medical attention.

KEYWORDS: dizziness; prevalence; epidemiology.

Bittar RSM, Mezzalira R, Grasel SS, Oiticica J. Dizziness profile and clinical features: a population based survey in São Paulo City, Brazil. MedicalExpress (São Paulo, online). 2015;2(1):M150106.

Received for publication on October 22 2014; First review completed on November 11 2014; Accepted for publication on December 152014

E-mail: jeanneramalho@uol.com.br

\section{INTRODUCTION}

The epidemiology of dizziness is crucial for clinical practice, because this symptom is one of the ten main reasons leading patients to seek medical attention at the emergency room. ${ }^{1,2}$ It is estimated that about $20 \%$ of patients who are seen by general practitioners have some kind of dizziness, ${ }^{3,4}$ which is the third most frequent symptom in a general health practice, after pain and fatigue. ${ }^{5}$

Until recently, there were no data on the prevalence of dizziness among the adult population of urban areas in Brazil. ${ }^{6}$ According to the last census (2010) by the Brazilian Institute of Geography and Statistics (IBGE), the population of the city of São Paulo was estimated at 11,253,503 residents ${ }^{7}$ within an area of $1,523 \mathrm{Km}^{2}$. São Paulo has the largest municipal GDP in Brazil, and is among the 10 wealthiest cities worldwide. São Paulo's economy outperforms cities such as Washington DC, Boston, Dallas, Atlanta or Hong

Presented at the American Academy of Otolaryngology-Head and Neck Surgery Foundation Annual Meeting, Orlando, Florida, September 21-24, 2014

DOI: $10.5935 /$ MedicalExpress.2015.01.06
Kong, and even whole countries such as Portugal or Finland. Social indicators show that $95.41 \%$ of the population aged 10 years or older is literate, and the life expectancy is about 76 years, comparable to life expectancy in North America.

Dizziness may be the cause of falls and of prolonged sickleave, with a major impact on morbidity and quality of life, and is responsible for economic losses. Therefore, population-based studies are helpful to implement public health strategies and to prevent conditions associated with or aggravated by dizziness.

To estimate the prevalence of dizziness among the population of São Paulo, one of the largest urban centers in Latin America, we developed a study based on a survey on the prevalence of Ménière's disease among the population in Southern Finland. ${ }^{8}$ A pioneer field survey was performed, where the researcher visited participants at home and conducted personal interviews to collect data for the questionnaire. Previously reported research by our center determined the population profile and showed that dizziness is related to elevated morbidity, and impacts the subjects' health among the population of São Paulo, Brazil. ${ }^{6}$ 
In this study our purpose was to analyze the clinical features of dizziness and their impact on daily activities.

\section{OBJECTIVES}

To estimate the prevalence of dizziness and to describe the clinical features and level of discomfort among the adult population of the city of São Paulo, Brazil.

\section{METHODS}

A cross-sectional epidemiological survey was conducted in the city of São Paulo, São Paulo, Brazil, between April and October 2012. In this field study, the researcher visited participants at home and conducted a personal interview to collect data for the questionnaire, completing a total of 1960 personal household interviews. The following variables were assessed: gender, age, clinical characteristics of dizziness, and dizziness disability index. ${ }^{9}$

\section{Statistical Analysis}

We used Pearson's Chi-square test to analyze the association of type of dizziness with age and gender, as well as the association of dizziness disability index with gender. The association of age, gender, and frequency of visits to the health care center were also tested with Pearson's Chi-square test. The distribution of the dizziness disability index among participants according to their educational level was tested with Independent T-Test for Means (equal variances), Independent Z-Test for Percentages. Results were considered to be statistically significant for $\mathrm{p}<0.05$.

\section{Study population}

The sample size was previously determined as follows: we assumed a dizziness prevalence of $10 \%$ with a precision of $2 \%$ and confidence interval of $95 \%$, an effect size of 2 and a $10 \%$ increase for possible losses. Using these assumptions, the sample size was set at 1901 adult residents. Based on the assumption that we would find $3-4$ residents per household, 633 homes were to be visited. Among the 13,193 census regions of the city of São Paulo, forty were randomly selected, representing the five geographical regions of the city (north, south, east, west and center), each of them participating with eight census regions. We evaluated the five geographic areas to assure sample diversity and to guarantee the inclusion of all socioeconomic and age groups. The random selection of the census regions was proportional to the respective population sizes, thus maintaining an equal level of likelihood.

Overall, we collected detailed data from 1960 participants (1008 households, mean: 2.2 adults/household). The study was carried out according to the European Society for Opinion and Marketing Research (ESOMAR) guidelines; the Ethics Committee of the University of São Paulo School of Medicine (protocol 0970/09) approved the study.

\section{RESULTS}

Dizziness prevalence was established at $42 \%$ (831 among 1960 respondents) in the city of Sao Paulo. Most of the respondents had recent dizziness complaints, $59 \%$ for no more than three years; $31 \%$ reported dizziness for just one year. Long lasting dizziness ( $>20$ years) was rare, accounting for only $3 \%$ of the participants. Peaks of dizziness were observed among two age groups: $49 \%$ among the $46-55$-yearold and $44 \%$ among elderly subjects ( $>65$ year-old). Vertigo was the most common complaint $(41 \%)$, followed by fluctuation, fainting, and imbalance $(27 \%, 18 \%$ and $14 \%$, respectively). While vertigo was more prevalent among the younger age groups, peaking among the 26-35-year-old, imbalance was more frequent among the older age groups, peaking in the elderly over 65 years, as shown in Fig. 1.

Vestibular vertigo was estimated at $8.3 \%$ with a strong female preponderance ( $\mathrm{p}<0.001)$ as shown in Fig. 2 .

Fig. 3 shows that Women complained more about discomfort and felt more handicapped $(\mathrm{P}<0.001)$. Overall $27 \%$ of the respondents reported disability due to dizziness, and $67 \%$ reported interruption of daily activities.

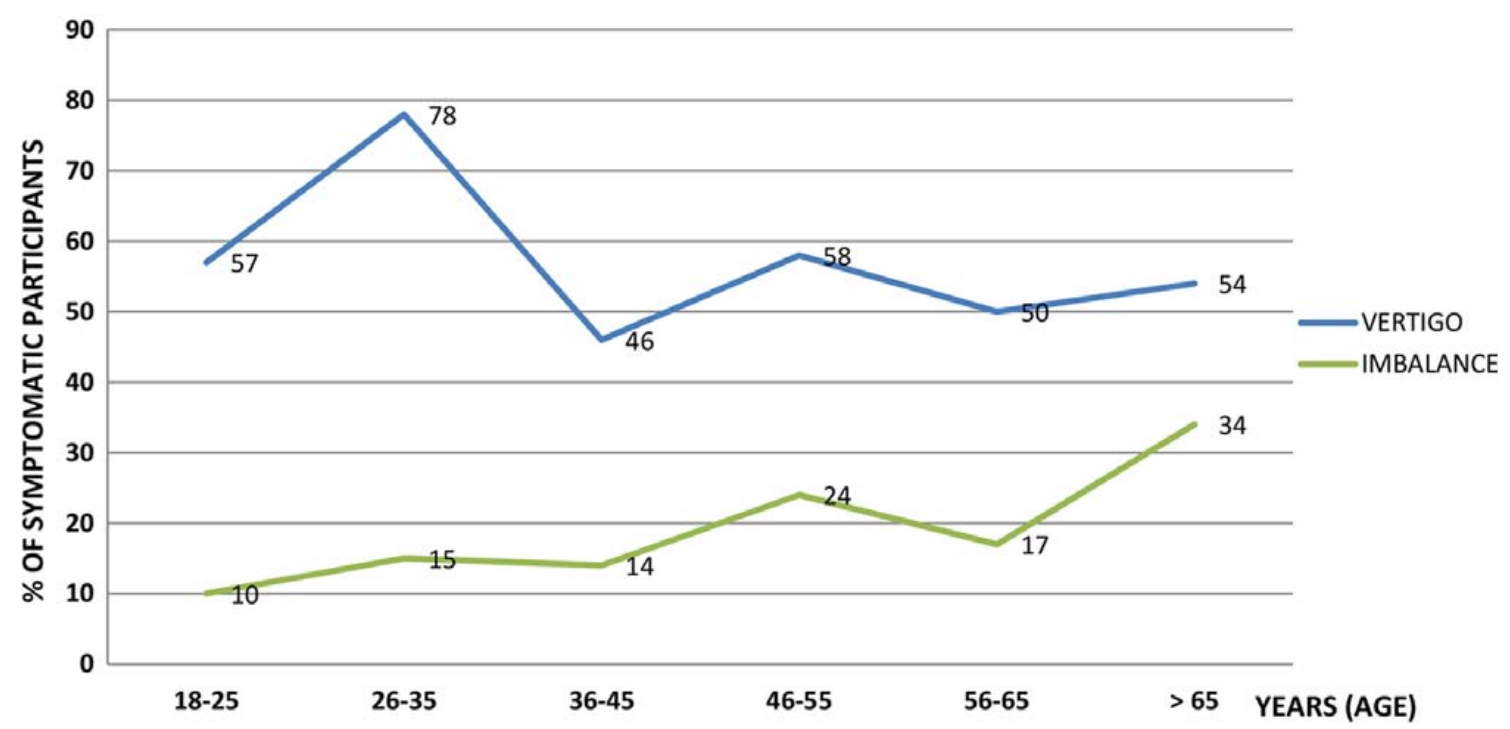

Figure 1 - Percentage of vertigo (343 respondents) and imbalance (114 respondents) among 831 respondents with dizziness, according to age. 


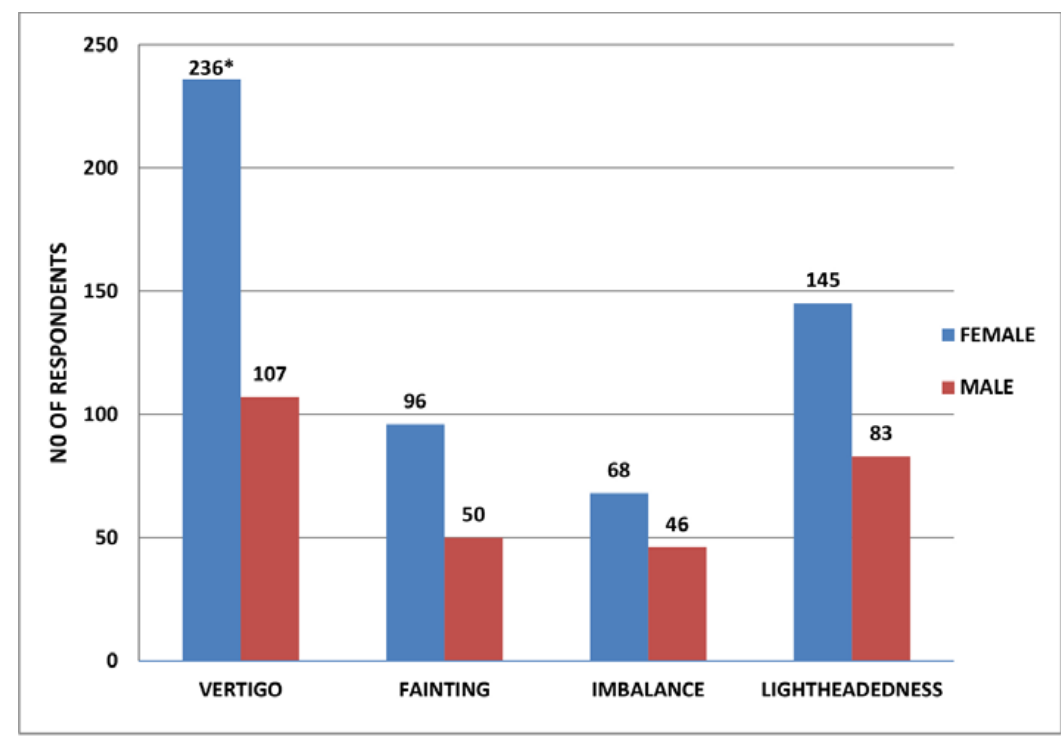

Figure 2 - Distribution of clinical characteristics of dizziness according to gender ( $* p<0.001)$.

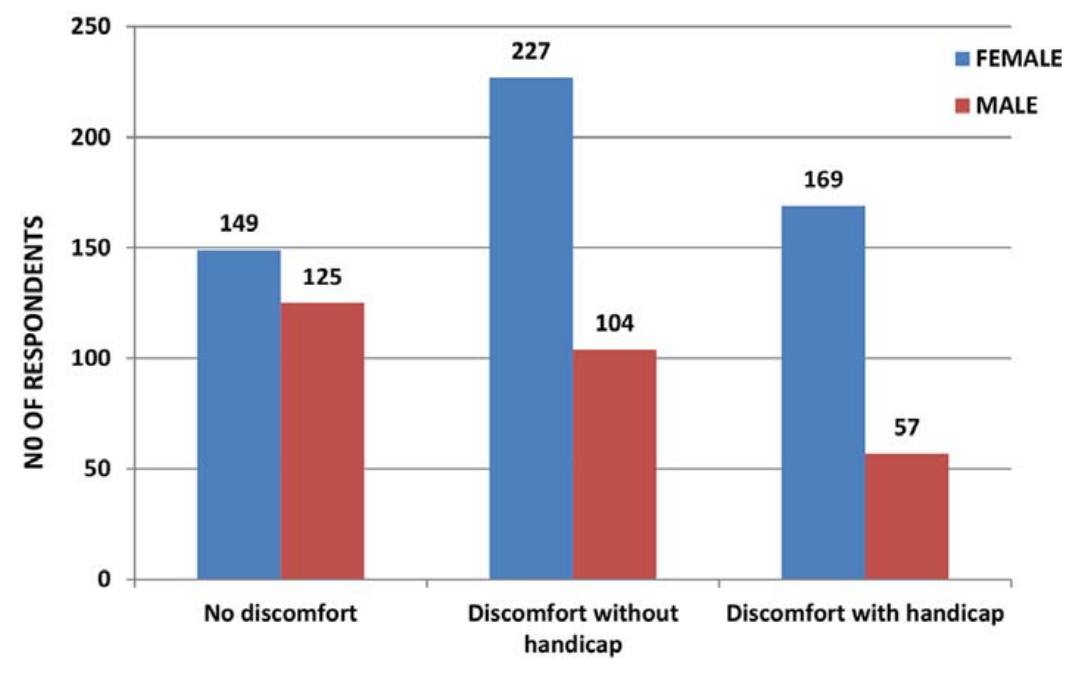

Figure 3 - Dizziness discomfort according to gender.

The dizziness disability index was significantly higher $(\mathrm{p}=0.0165)$ among subjects with a lower educational level (Fig. 4).

Only $46 \%$ of the symptomatic subjects sought medical attention. Females and the older age groups sought medical attention more frequently $(\mathrm{p}<0.001)$.

\section{DISCUSSION}

The epidemiological survey conducted in the city of São Paulo showed that vertigo was the most common type of dizziness ( $41 \%$ of the symptomatic subjects). Vertigo is known to be related to vestibular diseases, so the prevalence of vestibular disorders could be estimated at $8.3 \%$ of our study population which is consistent with other studies. ${ }^{10,11}$ Some epidemiological data was previously published in a Brazilian Journal. ${ }^{6}$ Among the younger population, vestibular symptoms predominated, probably related to lifestyle and diet choices in this age group. It is well known that increased ingestion of soft drinks, sugar, high fat diet, and fast food as well as drug use and poor sleep patterns predispose to vestibular symptoms, and may trigger migraine. $12,13,14$

As did other researchers, ${ }^{11,15}$ we observed a marked female preponderance for vertigo. However, other forms of dizziness such as fainting and light-headedness were also more frequent among females, but the differences were not statistically relevant. Women seem to be more sensitive to imbalance and vertigo, and feel a greater impact on their daily activities. Disability with handicap was reported by $27 \%$ of the respondents, mostly females. Feeling more handicapped, women sought medical attention more frequently in order to control the unpleasant or even scary symptoms as early as possible. Women seem to show peaks of dizziness and migraine according to hormonal changes during their lifetime. It increases in the perimenopausal transition. ${ }^{16}$ This period of life is also known as the peak for migraines, and we may speculate that this is triggered by sudden hormone level variations. ${ }^{17}$ 


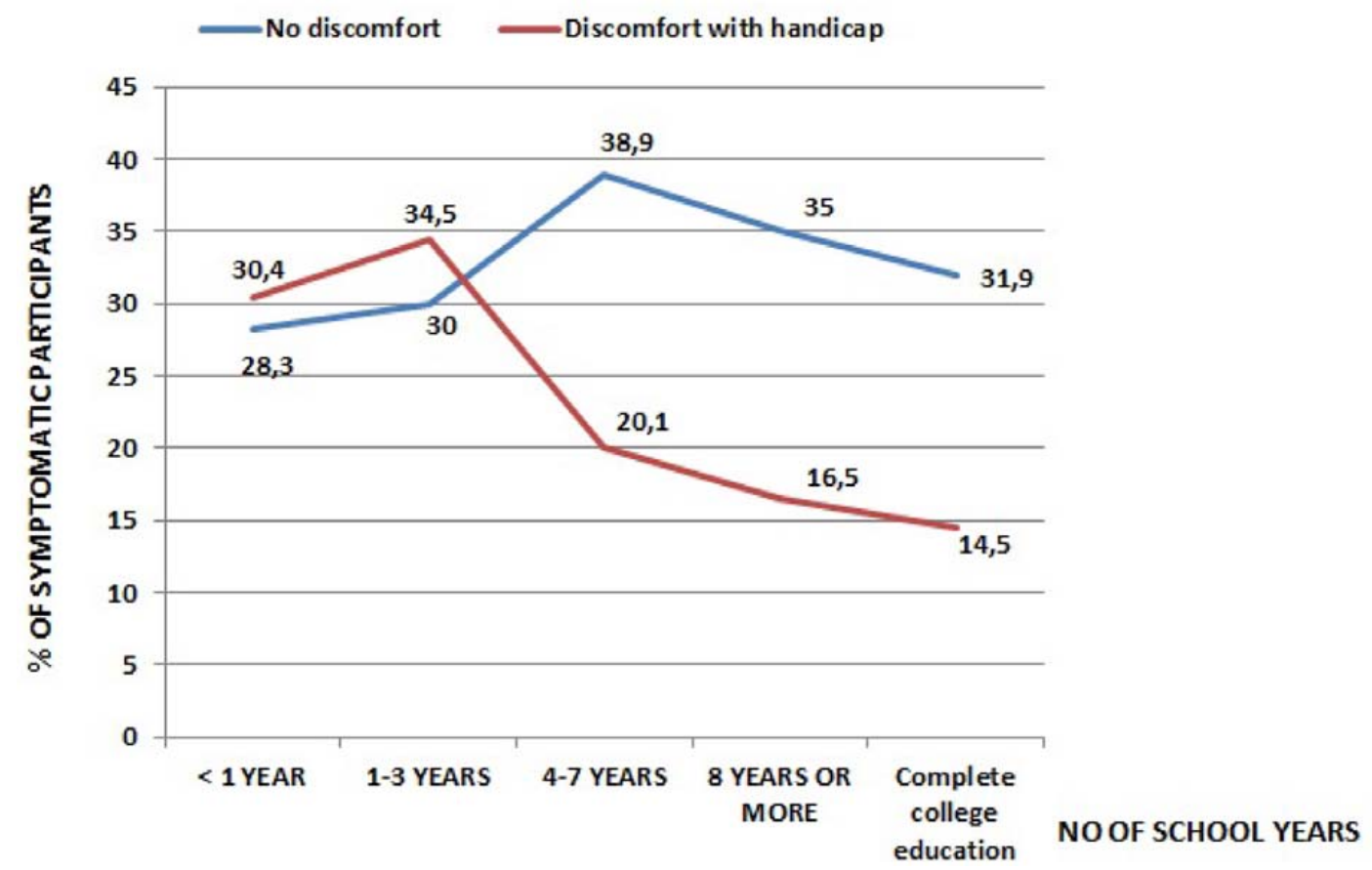

Figure 4 - Dizziness discomfort according to educational level $(n=831)$.

Symptoms such as imbalance, fainting, and fluctuation were found to increase with age, showing a higher impact of nonvestibular dizziness in the middle-aged and older population. Fluctuation and feeling of fainting are often associated with systemic diseases (cardiovascular and metabolic disorders, postural hypotension, ischemia) or with side effects of medication. ${ }^{18}$ Imbalance may also reflect aging of the human balance system including the vestibular organ, peripheral and central vestibular pathways.

Among 831 respondents with dizziness, 59\% reported this symptom for no more than three years. It appears that disorders with recurrent or long-lasting symptoms such as Meniere's disease were uncommon among the population in São Paulo. In other studies, Ménière's disease is found to be a rare condition among the general population, although often overestimated. The Rochester study reported a prevalence of 218 per 100,000 population in $1984{ }^{19}$ the Southern Finland study reported 513 per 100,000 population in $1999 .^{20}$

We found no impact of occupation on dizziness. In our population, dizziness was equally distributed among employed and unemployed within all types of jobs. Textile workers, who are thought to be more vulnerable to cervical vertigo, reported even less dizziness (19.5\%) than the overall population $(42 \%)$. This differs from other studies. ${ }^{21}$

We observed a marked impact of dizziness among subjects with a lower educational level. Discomfort with handicap was highest among respondents who completed up to three school years (35\% of participants), and decreased continuously with increasing educational level of the respondent, bothering only $15 \%$ of subjects with a complete college education $(p=0.0165)$. The higher impact of dizziness among less educated respondents shows their vulnerability to physical illness and higher psychological distress. Dizziness is a symptom often interpreted as a serious condition such as, for instance, stroke or ischemia.
Surprisingly, 54\% of the "dizzy" population had never seen a physician or health care facility for this symptom. Women (51\%) and elderly (61\% of those over 65 year-old) with dizziness sought medical attention more frequently. As men felt less impact of dizziness in their daily life $(p<0.001)$, they probably had no reason to see a doctor for the symptom. Among the 18-25 year old respondents with dizziness, only $27 \%$ sought medical attention. As young adults had less frequent and recurrent symptoms than the elderly, ${ }^{6}$ they may experience vertigo as a self-limited condition that does not demand medical investigation. Elderly people usually have more comorbidities and use more medication. Therefore they see the health care center more frequently in order to get prescriptions and have the opportunity to see a doctor and to report their dizziness.

\section{CONCLUSION}

The prevalence of dizziness in São Paulo, Brazil, was established at $42 \%$. Among the symptomatic subjects, $67 \%$ reported interruption of daily activities, but only $46 \%$ of them sought medical attention.

\section{PERFIL E CARACTERÍSTICAS CLÍNICAS DE TONTURA: UM ESTUDO BASEADO NA POPULAÇÃO DA CIDADE DE SÃO PAULO, BRASIL}

\section{RESUMO}

OBJETIVO: Estudo epidemiológico transversal, desenvolvido para avaliar a prevalência de tontura entre a população adulta da cidade de São Paulo, Brasil, e descrever as características clínicas e nível de desconforto.

MÉTODO: Estudo de base populacional na cidade de São Paulo, Brasil, entre abril e outubro de 2012. Um total de 1.960 entrevistas domiciliares foram concluídas. As seguintes variáveis foram analisadas: sexo, idade, características clínicas de tonturas e vertigens, índice de incapacidade. Os testes qui- 
quadrado, " $\mathrm{t}$ " de Student, Tukey e regressão logística foram utilizados para análise estatística.

RESULTADOS: A prevalência de tontura em São Paulo foi de $42 \%$. Em dois grupos etários, foram observados picos de tontura: $49 \%$ entre os 46 e 55 anos de idade e $44 \%$ entre os idosos (> 65 anos de idade). Vertigem vestibular foi detectada em $8,3 \%$, com uma forte preponderância para o sexo feminino ( $\mathrm{p}<0,001)$. Os sintomas causaram deficiência em $27 \%$ dos entrevistados, com predominância entre as mulheres $(\mathrm{p}<0,001)$, que procuraram atendimento médico com mais freqüência $(\mathrm{p}<0,001)$. O índice de incapacidade por tontura foi significativamente maior $(\mathrm{p}=0,0165)$ entre os indivíduos com menor escolaridade. Não houve correlação entre desconforto por tontura e o tipo de emprego.

CONCLUSÃO: A prevalência de tontura em São Paulo, Brasil, foi estabelecida em $42 \%$. Entre os pacientes sintomáticos, $67 \%$ relataram a interrupção das atividades diárias, mas apenas $46 \%$ deles procuraram atendimento médico.

UNITERMOS: tontura; prevalência; epidemiologia.

\section{REFERENCES}

1. Moulin T, Sablot D, Vidry E, Belahsen F, Berger E, Lemounaud P, et al. Impact of emergency room neurologists on patient management and outcome. Eur Neurol. 2003;50(4):207-14.

2. Schappert SM, Nelson C. National Ambulatory Medical Care Survey: 1995-96 summary. Vital Health Stat. 1999;Nov(142), i-iv, 1-22.

3. van der Windt DA, Dunn KM, Spies-Dorgelo MN, Mallen CD, Blankenstein $\mathrm{AH}$, Stalman WA. Impact of physical symptoms on perceived health in the community. J Psychosom Res. 2008;64(3):265-74

4. Yardley L, Owen N, Nazareth I, Luxon L. Prevalence and presentation of dizziness in a general practice community sample of working age people. Br J Gen Pract. 1998:48(429):1131-5.

5. Kroenke K, Mangelsdorff AD. Common symptoms in ambulatory care: incidence, evaluation, therapy, and outcome. Am J Med. 1989;86(3):262-6.

6. Bittar RS, Oiticica I, Bottino MA, Ganança FF, Dimitrov R. Population epidemiological study on the prevalence of dizziness in the city of São Paulo. Braz J Otorhinolaryngol. 2013;79(6):688-98.
7. IBGE. 2010; Censo Demográfico da População da Cidade de São Paulo. 2010; Available from: http://www.ibge.gov.br/home/presidencia/ noticias /noticia_visualiza.php?id_noticia=2204\&id_pagina $=1$.

8. Havia M, Kentala E, Pyykko I. Prevalence of Meniere's disease in general population of Southern Finland. Otolaryngol Head Neck Surg. 2005;133(5):762-8

9. Shepard NT, Telian SA, Smith-Wheelock M. Habituation and balance retraining therapy. A retrospective review. Neurol Clin. 1990;8(2):459-75.

10. Neuhauser HK, von Brevern M, Radtke A, Lezius F, Feldmann M, Ziese T. Epidemiology of vestibular vertigo: a neurotologic survey of the general population. Neurology. 2005;65(6):898-904.

11. Neuhauser HK, Lempert T. Vertigo: epidemiologic aspects. Semin Neurol. 2009;29(5):473-81.

12. Hogan A, McLellan L, Bauman A. Health promotion needs of young people with disabilities-a population study. Disabil Rehabil. 2000;22(8):352-7.

13. Millichap JG, Yee MM. The diet factor in pediatric and adolescent migraine. Pediatr Neurol. 2003;28(1):9-15.

14. Santos MA, Bittar RSM. Vertigo and metabolic disorders. International Tinnitus Journal. 2012;17(1):16-20.

15. Lai YT, Wang TC, Chuang LJ, Chen MH, Wang PC. Epidemiology of vertigo: a National Survey. Otolaryngol Head Neck Surg. 2011;145(1):110-6

16. Park JH, Viirre E. Vestibular migraine may be an important cause of dizziness/vertigo in perimenopausal period. Medical Hypotheses. 2010;75:409-14.

17. Scharfman HE, MacLusky NJ. Estrogen-growth factor interactions and their contributions to neurological disorders. Headache. 2008;48(Suppl 2):S77-S89.

18. Byrne D. Assessment of the dizzy patient. Aust Fam Physician. 2002;31(8):722-7.

19. Wladislavosky-Waserman P, Facer GW, Mokri B, Kurland LT. Meniere's disease: a 30-year epidemiologic and clinical study in Rochester Mn, 19511980. Laryngoscope. 1984;94(8):1098-102.

20. Kotimäki J, Sorri M, Aantaa E, Nuutinen J. Prevalence of Meniere disease in Finland. Laryngoscope. 1999;109(5):748-53.

21. Wrisley DM, Sparto PJ, Whitney SL, Furman JM. Cervicogenic dizziness: a review of diagnosis and treatment. J Orthop Sports Phys Ther 2000;30:755-66. 